Copyright (C) 2021 University of Bucharest Printed in Romania. All rights reserved

ISSN print: $1224-5984$

ISSN online: $2248-3942$
Rom Biotechnol Lett. 2021; 26(1): 2340-2346 doi: $10.25083 / \mathrm{rbl} / 26.1 / 2340.2346$

Received for publication, September, 12, 2019

Accepted, December, 27, 2019

Original paper

\title{
Clinical and microbiological features of carious dentin in immature permanent molars
}

\author{
RALUCA-PAULA VACARU ${ }^{1,2}$, SILVIA PER ${ }^{1,2}$, IOANA-ANDREEA STANCIU ${ }^{2}$, ANETA \\ MUNTEANU $^{2}$, DANIELA MIRICESCU ${ }^{3}$, ALEXANDRA TOTAN ${ }^{3}$, MIHAELA TĂNASE ${ }^{2}$, \\ ANDREEA CRISTIANA DIDILESCU ${ }^{*}$
}

${ }^{1}$ Division of Embryology, Faculty of Dental Medicine, "Carol Davila" University of Medicine and Pharmacy, Bucharest, Romania

${ }^{2}$ Division of Pedodontics, Faculty of Dental Medicine, "Carol Davila" University of Medicine and Pharmacy, Bucharest, Romania

${ }^{3}$ Division of Biochemistry, Faculty of Dental Medicine, "Carol Davila" University of Medicine and Pharmacy, Bucharest, Romania

\begin{abstract}
The present study aimed to assess the dentin lesion activity in non-superficial carious lesions affecting vital immature permanent molars and to investigate possible associations between microbiological status, clinical dentin alterations, and salivary cortisol levels.

Study sample consisted of a total number of 22 immature permanent molars of 13 children. After clinical estimation of lesion activity, a fine sample of deep dentin layer was removed and inoculated on bacteria tests. Salivary cortisol was assessed using an ELISA method.

Most molars were diagnosed as actively carious progressing. There was a gradual increase in the bacterial counts, with higher lactobacilli $(p=0.001)$ and mutans streptococci $(p=0.045)$ loads in deep carious lesions, without any salivary cortisol level association. The findings of the present study discriminate between different clinical characteristics of carious lesions, supporting a conservative cavity preparation approach.
\end{abstract}

Keywords Deep caries, dentin, microbiology, salivary cortisol, children.

To cite this article: VACARU RP, PER S, STANCIU IA, MUNTEANU A, MIRICESCU D, TOTAN A, TĂNASE M, DIDILESCU AC. Clinical and microbiological features of carious dentin in immature permanent molars. Rom Biotechnol Lett. 2021; 26(1): 2340-2346. DOI: 10.25083/rbl/26.1/2340.2346

*Corresponding author: ANDREEA CRISTIANA DIDILESCU, Division of Embryology, Faculty of Dental Medicine, "Carol Davila" University of Medicine and Pharmacy, Bucharest, Romania E-mail: andreea.didilescu@umfcd.ro 


\section{Introduction}

Dental caries is one of the highly prevalent chronic diseases worldwide. The global prevalence of untreated dentin carious lesions in the permanent dentition was $35.4 \%$ in 2010 , reaching its peak incidence at 25 years-old (KASSEBAUM et al [1]). Despite the fact that we witness a global decreasing trend since 1990, in some countries dental caries incidence it is still high (KASSEBAUM et al [1]), Romania being one of the countries with a rate of decay higher than the average for European Region, in the 12 years-old group (MOREIRA [2]). Worldwide, median mean DMFT values for 12 years-old vary from 0.9 to 2.1 . In 12 years-olds, the median prevalence of cavitated dentin carious lesions reaches greater values, being $42.2 \%$ in low income countries with a peak of $69.4 \%$ for upper-middle income countries, one of the main reasons being the high sugar intake (FRENCKEN et al [3]). Other factors, such as low socioeconomic status, elevated salivary cortisol expression and high counts of cariogenic bacteria, have also been cited as being significantly associated with dental caries (BOYCE et al [4]).

One of the most affected permanent teeth is the first permanent molar, which erupts around 6 years-old (ONG $\&$ BLEAKLEY [5]). Although the second permanent molar is less impaired, premature loss of either tooth may have severe consequences, affecting occlusal relationships through drifting, tilting and rotations of the adjacent teeth, as well as bone development (BHAYAT et al [6]).

The bacteria from the biofilm can easily progress into the dentin when the enamel break-down occurs, and if the cariogenic factors persist, the progression of caries continues its way to the pulpal tissue (CARLOS \& GITTELSOHN [7]). When managing deep carious lesions, a major area of concern is finding an effective treatment that wouldn't compromise the vitality of the pulp. Frequently, complete caries removal of these lesions might cause a pulp exposure; therefore arresting the carious activity, by choosing selective caries removal and indirect pulp treatment, is a more conservative approach (LEKSELL et al [8]). This creates favourable conditions for tertiary dentin formation and maintaining pulp vitality, an important condition, especially for immature permanent teeth which need to complete their apexogenesis (BJORNDAL et al [9]). It is, therefore, important to understand the intimate mechanism of caries progression, as well as the relationship between the clinical aspect of the carious dentin, bacterial colonization and subjective symptomatology. Previous studies have shown a significant association between consistency and moisture of the infected dentine and bacterial load (BJORNDAL et al, KIDD et al, PETROU et al [9-11]). However, to our knowledge, no information regarding the relationship between salivary stress markers levels and characteristics of the carious lesion is available in the literature.
The primary aim of the present study was to assess the dentin lesion activity in carious lesions affecting at least $1 / 2$ of dentin thickness in immature permanent molars (IPM), based on different clinical criteria. A secondary aim was to investigate possible associations between microbiological status, clinical dentin alterations, and salivary cortisol levels.

\section{Methods}

The study was approved by the Ethics Committee of the Carol Davila University of Medicine and Pharmacy (no. 137/6.06.2017 and 188/28.01.2019). The parents or legal guardians of the children were informed about the objectives of the study and signed a free informed consent form, permitting the participation of minors. Study sample consisted of 13 healthy children, aged 7 to 15 -years-old (mean 9.07, SD 2.13), presenting deep carious lesions on IPM, who were recruited from the Division of Pedodontics, Faculty of Dental Medicine, Carol Davila University of Medicine and Pharmacy, Bucharest. Pretreatment clinical and radiographical assessments were performed to classify lesion size and to exclude pulp pathology. A cold pulp vitality test (Pulp Spray, Cerkamed, Poland) was used to confirm pulp sensibility.

\section{Eligibility criteria}

IPM selection was based on clinical and radiographical assessments. The intervention was performed on vital IPM affected by uncomplicated primary carious lesions, without any previous treatment. The tooth was considered eligible if the carious lesion was radiographically affecting at least half of dentin thickness. Exclusion criteria included previously treated molars, molars presenting developmental abnormalities (enamel hypoplasia/hypomineralisation) or signs of pulpal involvement (clinical pulp exposure, history of spontaneous pain and sensitivity to percussion, altered responses to vitality tests, presence of swelling of periodontal tissues or fistulas, modified tooth colour, radiographic signs of pulp necrosis or infection of the apical periodontal space).

\section{Saliva sampling}

Unstimulated whole saliva was collected using the passive drool method (PUTNAM et al [12]). Patients were asked to pool saliva in their mouth and deposit it in $30 \mathrm{ml}$ sterile polypropylene culture tubes. A minimum of $1 \mathrm{ml}$ of saliva was collected for each patient. In order to standardize the time of collection, it was done two hours after waking up, between 8.00 AM and 11.00 AM. The parents were advised to supervise their children not to eat, drink or brush their teeth before collection. Saliva samples were centrifuged at $3500 \mathrm{xg}$ for $15 \mathrm{~min}$. Saliva supernatants were collected and stored at $-80^{\circ} \mathrm{C}$ for later analysis. Salivary cortisol was assessed using ELISA method (NovaTec Immundiagnostica GmbH, REF DSNOV20). 


\section{Treatment protocol}

The intervention was performed in the same day. At the beginning, the tooth was isolated, washed with saline and dried with cotton swabs. Thereafter, a cavity opening was performed using high-speed equipment for enamel, if necessary. Peripheral dentin was completely removed, along with the central cariogenic biomass and superficial part of the necrotic, demineralized dentin, using low-speed burs and excavators. Stepwise excavation continues elimination of superficial part of the necrotic dentin until the operator considered that pulp exposure would occur if excavation continues, in which case a layer of soft carious dentin was left on the cavity floor. Following rinsing of the cavity with saline, and mild drying with air spray and cotton swabs of cavity surfaces, a clinical evaluation of the remaining carious dentin was performed and a fine layer of deep dentin was carefully removed with a sterilized excavator. Afterwards, a calcium silicatebased pulp capping agent (Theracal LC, Bisco, USA) was applied on the floor of the cavity. The cavity was then temporary sealed with glass-ionomer cement (Fuji IX, GC, Japan).

\section{Clinical assessments}

The clinical evaluation of the remaining carious dentin was performed using the following criteria (BJORNDAL et al [9]): colour, moisture, consistency. The colour of the remaining central carious dentin was evaluated as light yellow, yellow, light brown, dark brown or black (CARLOS \& GITTELSOHN [7]). After a mild air dry of the tooth surface, the degree of moisture of the carious tissue was assessed and classified as either wet or dry dentin. The dentin consistency was considered based on probe testing (BJORNDAL et al [9]): very soft, if the probe easily penetrated dentin with fragment loss of carious tissue; soft, if no resistance was held when removing the probe penetrating the carious tissue; firm, if there was a slight resistance when removing the probe; hard, if the consistency was comparable to unaffected dentin. Overall, estimation on lesion activity in clinical terms was done as follows: actively progressing - light yellow/yellow, wet, very soft/soft dentin; slowly progressing - light brown/dark brown, dry, firm dentin; arrested - dark brown/black, dry, firm/hard dentin (CARLOS \& GITTELSOHN [7]).

\section{Microbiological evaluation}

A fine sample of deep dentin layer was removed with a sterilized excavator, placed in a sterile container, and mixed with $2 \mathrm{ml}$ distilled water. The mixture was inoculated on chair-side microbiological tests (CRT bacteria, Ivoclar Vivadent, Liechtenstein), $1 \mathrm{ml}$ for each side (PETROU et al [11]). The microbiological tests were immediately placed in the incubator (Cultura Incubator, Ivoclar Vivadent, Liechtenstein) according to the manufacturer's instructions, for 48 hours. Semiquantitative assessment of colony forming units (CFU) of lactobacilli and streptococci was performed by comparing the results with the pictures provided by the manufacturer. The microbiological results were classified as less or more than $10^{5}$ bacterial counts (PETROU et al [11]).

\section{Statistical analysis}

Data distributions were expressed as means, standard deviations (SD), frequencies and percentages. Intergroup comparisons were done using the oneway ANOVA test and independent student $t$-test for continuous measures. The Pearson Chi-squared test was used for categorical measures. Fisher's exact test was used when the expected frequency of any cell in the table was $<5$. Statistical analyses were performed using Stata/IC 14 (StataCorp. 2015. Statistical Software. College Station, TX, USA). A $p$-value of 0.05 was considered statistically significant.

\section{Results}

A total number of 22 IPM of 13 children fulfilled the eligibility criteria, 19 first IPM $(86,36 \%)$ and 3 second IPM $(13,63 \%)$. Mandibular molars were mostly affected (59.09\% of carious lesions). The carious lesion affected one surface of the tooth in $63.64 \%$ of cases, and two surfaces in $36.36 \%$. The lesion depth was approximately diagnosed on radiographies as exceeding 3/4 of dentin thickness in $27.27 \%$ of cases $(n=6)$, while in $72.73 \%$ of teeth, this exceeded half of the dentin thickness.

Student $t$-test test showed significant differences between mean ages of children with respect to caries depth assessed radiographically, that is, children with deeper caries lesions were significantly older $(M=10.83$; $\mathrm{SD}=2.23)$, than children with less severe lesions $(\mathrm{M}=8.19$; $\mathrm{SD}=1.17) ; \mathrm{t}(20)=-3.67, p=0.0015$.

Of all molars treated, $45.45 \%$ presented sensibility to cold and sweet prior to the intervention, which was positively associated with the radiological depth of the carious lesion $(p=0.056)$. Furthermore, the response to cold pulpal test was normal in $68.18 \%$ of cases, and had decreased or increased sensitivity in $9.09 \%$ and $22.73 \%$ of cases, respectively. The response to cold pulpal test was positively associated with the radiological depth of the carious lesion $(p=0.004)$. There were no significant associations between clinical assessment of carious activity and pre-treatment sensitivity or response to cold pulpal test.

Dentin consistency decreased consistently with caries progression $(p=0.055)$, while no significant relationship was observed between lesion depth assessed on X-ray and moisture, colour and carious activity, respectively.

Most molars were diagnosed as actively carious progressing $(54.55 \%, \mathrm{n}=12)$, followed by slowly carious progressing $(31.82 \%, \mathrm{n}=7)$, and arrested carious lesions $(13.64 \%, \mathrm{n}=3)$. The most frequent colour was yellow $(36.36 \%, \mathrm{n}=8)$, followed by dark brown $(27.27 \%, \mathrm{n}=6)$, 
light yellow $(18.18 \%, \mathrm{n}=4)$, light brown $(9.09 \%, \mathrm{n}=2)$, and black $(9.09 \%, \mathrm{n}=2)$. The most detected consistency was "very soft" in 8 cases $(36.36 \%)$, followed by "firm" in $6(27.27 \%)$, "soft" (intermediary) in $5(22.73 \%)$, and hard in $5(13.64 \%)$. In 13 samples $(59.09 \%)$, the lesions were wet, while in $9(40.91 \%)$, they were dry. Wet lesions were pale coloured $(p=0.011)$, and softer than other types $(p<0.001)$. Darker colours were significantly associated with harder lesions ( $p=0.016)$.

There was a gradual increase in the bacterial counts, consistent with radiographic findings of lesions depth, with significantly higher lactobacilli load ( $p=0.001)$, and marginally significant mutans streptococci load $(p=0.045)$ in deep carious lesions. In $45.45 \%$ of cases, mutans streptococci growth was not observed, while lactobacilli harboured all dentin samples.
The associations between clinical assessments of carious dentin and microbiological loads are presented in Tables 1 and 2 . Softer lesions yielded significantly more lactobacilli than harder lesions $(p=0.001)$. Only very soft lesions harboured $>10^{5}$ of cariogenic bacteria. Lesions classified as wet harboured significantly more lactobacilli than dryer lesions $(p=0.046)$. Overall, actively progressing lesions yielded significantly more lactobacilli than slowly progressing and arrested lesions, respectively $(p=0.031)$. A similar pattern was observed for mutans streptococci growth, although without significance.

The mean levels of salivary cortisol were $6.82 \pm 2.95 \mathrm{ng} / \mathrm{ml}$ (range 3.39 to 12.76 ). No significant associations between salivary cortisol levels and any clinical assessment or bacterial loads were recorded.

Table 1. Relationship between lactobacilli counts and caries progression, dentin colour, surface consistency and moisture

\begin{tabular}{|c|c|c|c|c|c|c|c|c|c|c|c|c|c|c|c|c|c|c|}
\hline \multirow[t]{2}{*}{ LB levels } & \multicolumn{3}{|c|}{ Caries progression (\%) } & $p$ & \multicolumn{5}{|c|}{ Colour (\%) } & $p$ & \multicolumn{4}{|c|}{ Consistency (\%) } & $p$ & \multicolumn{2}{|c|}{ Moisture (\%) } & $p$ \\
\hline & $\mathrm{AP}$ & SP & $\mathrm{A}$ & \multirow{3}{*}{$\stackrel{*}{*}$} & LY & $\mathrm{Y}$ & LB & DB & B & \multirow{3}{*}{ กั } & VS & $\mathrm{S}$ & $\mathrm{F}$ & $\mathrm{H}$ & \multirow{3}{*}{$\begin{array}{l}\overline{8} \\
\end{array}$} & $\mathrm{~W}$ & $\mathrm{D}$ & \multirow{3}{*}{ 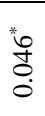 } \\
\hline$<10^{5}$ & 50 & 100 & 100 & & 50 & 62.50 & 50 & 100 & 100 & & 25 & 100 & 100 & 100 & & 53.85 & 100 & \\
\hline$>10^{5}$ & 50 & 0 & 0 & & 50 & 37.50 & 50 & 0 & 0 & & 75 & 0 & 0 & 0 & & 46.15 & 0 & \\
\hline
\end{tabular}

LB, Lactobacillus spp.; AP, Actively progressing; SP, Slowly progressing; A, Arrested; LY, Light yellow; Y, Yellow; LB, Light brown; DB, Dark brown; B, Black; VS, Very soft; S, Soft; F, Firm; H, Hard; W, Wet; D, Dry; * Statistically significant.

Table 2. Relationship between mutans streptococci counts and caries progression, dentin colour, surface consistency and moisture

\begin{tabular}{|c|c|c|c|c|c|c|c|c|c|c|c|c|c|c|c|c|c|c|}
\hline \multirow[t]{2}{*}{ MS levels } & \multicolumn{3}{|c|}{ Caries progression (\%) } & $p$ & \multicolumn{5}{|c|}{ Colour (\%) } & $p$ & \multicolumn{4}{|c|}{ Consistency (\%) } & $p$ & \multicolumn{2}{|c|}{ Moisture (\%) } & $p$ \\
\hline & AP & SP & $\mathrm{A}$ & \multirow{3}{*}{$\tilde{n}$} & LY & $\mathrm{Y}$ & LB & DB & $\mathrm{B}$ & \multirow{3}{*}{ ले } & $\mathrm{VS}$ & $\mathrm{S}$ & $\mathrm{F}$ & $\mathrm{H}$ & \multirow{3}{*}{ ले } & $\mathrm{W}$ & $\mathrm{D}$ & \multirow{3}{*}{ ñ } \\
\hline$<10^{5}$ & 71.53 & 100 & 100 & & 100 & 50 & 0 & 100 & 100 & & 50 & 100 & 100 & 100 & & 75 & 100 & \\
\hline$>10^{5}$ & 28.57 & 0 & 0 & & 0 & 50 & 0 & 0 & 0 & & 50 & 0 & 0 & 0 & & 25 & 0 & \\
\hline
\end{tabular}

MS, Mutans streptococci; AP, Actively progressing; SP, Slowly progressing; A, Arrested; LY, Light yellow; Y, Yellow; LB, Light brown; DB, Dark brown; B, Black; VS, Very soft; S, Soft; F, Firm; H, Hard; W, Wet; D, Dry.

\section{Discussions}

The primary aim of the present study was to assess the dentin lesion activity in non-superficial carious lesions affecting vital IPM. Our findings showed the progressive pattern of dental caries, that is, deeper carious lesions were observed in children of older ages. This is supported by studies demonstrating that when a cariogenic environment is persisting without any control of its causative factors being provided, and in absence of proper treatment, the cariogenic biofilm actively promotes progression of the lesion, gradually affecting tooth structure. It eventually leads to pulp inflammation and bacterial penetration into the pulp cavity, followed by pulp necrosis and apical periodontitis (BJØRNDAL \& THYLSTRUP [13]). This is of particular interest when treating children, since their teeth remain immature up to 2-4 years after emergence in the oral cavity, making them more vulnerable to cariogenic attack (LEONE \& OPPENHEIM [14]).
The present study showed positive associations between pretreatment sensitivity, response to pulp vitality tests, and radiographical lesion depth, although it was shown that the relationship between clinical signs and symptoms, and pulp histology is poor (MEJARE et al, DUMMER et al, GARFUNKEL et al [15-17]). Ricucci, Loghin [18] have recently demonstrated a relationship between clinical diagnosis and histological findings, especially for the cases with normal pulp and reversible pulpitis. Pulp-saving approaches have been suggested in teeth that only present mild sensitivity to cold or sweet stimuli, with responses to pulp sensibility tests within normal limits or slightly exaggerated, and with no history of spontaneous pain or signs of periradicular alterations.

Important issues when treating deep carious lesions in immature permanent teeth without signs of pulp involvement, are maintaining pulp vitality and avoiding the risk of pulp exposure by complete caries removal, that might compromise the success rate of the treatment (MALTZ et al, LEKSELL et al, RICKETTS et al [8, 19, 
20]). Therefore, different approaches have been recommended in order to overcome this risk, such as selective removal to firm dentin, selective removal to soft dentin or stepwise removal (SCHWENDICKE et al [21]). However, the management of deep carious lesions implies some difficulties, such as imprecise measurement of the actual lesion depth or assessment of bacterial infection. In absence of histological analysis, the true pulp health status cannot be determined by clinical signs, symptoms or radiologic appearance (SABER et al [22]).

Currently, practitioners are advised to remove only the infected outer carious dentin, in order to avoid accidental pulp exposure (SCHWENDICKE et al [21]). Clinical differentiation of the infected and demineralized dentin is difficult to be achieved, especially by a non-experienced practitioner (SCHWENDICKE \& INNES [23]). Characteristics, such as dentin quality, lesion depth, corroborated with clinical symptoms, both subjective and objective, might easily guide the clinician into distinguishing between the dentin types (SCHWENDICKE et al, RICKETTS et al [24, 25]). Our findings showing that bacterial load, especially lactobacilli growth, increases gradually as the lesion progresses towards dental pulp, are supported by Kidd's et al observations (KIDD et al [10]).

The relationship between lesion depth and dentin consistency is an important aspect to be taken into consideration when treating deep carious lesions, since deeper lesions tended to have softer dentin. More important, softer dentin consistency seemed to be significantly associated with higher bacterial load, especially lactobacilli. Dentin colour didn't appear discriminatory, as there were no associations with the bacterial load. In a recent study, the meta-analyses and effect size calculations data suggested that hardness tactile clinical examination has more discriminatory power in comparison to the dentin colour evaluation (HON et al [26]). Based on moisture, wet lesions harboured significantly higher bacterial load than dryer lesions. These results are in agreement with the observations of Kidd, JoystonBechal [10], Bjorndal, Larsen [9] and Orhan, Oz [27], showing that soft and wet dentin is a favourable environment for the growth of cariogenic bacteria, while hard and dry lesions are not heavily infected. Therefore, the most relevant clinical criteria that may guide the practitioner in differentiating infected dentin from affected dentin are its consistency and moisture content. Overall, our study confirmed that actively progressing caries correspond to higher levels of microbial infection of the dentin, arrested caries having the lowest levels (BJORNDAL et al, ZANATA et al [9, 28]).

In the present study, streptococci colonization did not correlate with dentin consistency, colour or moisture, lesions activity or depth, as opposed to other studies (KIDD et al [10]). However, our results are supported by other studies showing that lactobacilli are the dominant cariogenic species in deep carious lesions in permanent teeth (ORHAN et al, 2008, HAHN et al, 1991, LOVE \& JENKINSON [27, 29, 30]). Dentin hardness, as compared to dentin colour, proved to be more reliable when microbial differences were evaluated (HON et al [26]).

Studies performed on deciduous teeth indicated that mutans streptococci counts are higher than lactobacilli in deep carious lesions (ORHAN et al, AYNA et al [27, 31]). Ayna, Celenk [31] suggested that the reason for this difference lays in the fact that primary teeth have smaller sizes, lesions are more shallow, carious lesions have larger openings, which allows oxygen diffusion from saliva. Since lactobacilli are strictly anaerobic and highly sensitive to $\mathrm{pH}$ variations, their growth might be diminished.

The mean salivary cortisol values found by our study correspond to reference values reported in the literature (TORNHAGE [32]). Although there are controversies about the association between stress-related changes in saliva and caries (TIKHONOVA et al [33]), there are some studies reporting a positive relationship between salivary cortisol levels and carious experience in children (PANI et al, BARBOSA et al, BOYCE et al, RAI et al [4, 34-36]). However, to our knowledge, possible associations between salivary cortisol levels and clinical characteristics of deep caries in permanent molars have not been previously tested.

In our study, lack of significance might be due to small sample size. Larger scale studies may provide more conclusive results. Another limitation, which should be considered when assessing these results, is that we used semi-quantitative assessments of microbial CFU.

\section{Conclusions}

The findings of the present study are important for the operative management of dental caries, as they discriminate, based on microbiological content, between different clinical characteristics of deep carious lesions, supporting the current trends of a more conservative and pulp-aware cavity preparation approach. Consistency and moisture are the most important features that need to be taken into consideration when treating deep carious lesions. Colour, although frequently used by clinicians as guidance, did not provide useful information on the bacterial load and how active a lesion is, although darker lesions tended to have lower bacterial load.

\section{Abbreviations}

IPM: immature permanent molars

\section{Conflict of Interest disclosure}

There are no known conflicts of interest in the publication of this article. All authors have read and 
approved the manuscript. All authors have equally contributed to the present work.

\section{Acknowledgement}

This work was supported by a grant of Ministry of Research and Innovation, CNCS - UEFISCDI, project number PN-III-P4-ID-PCE-2016-0506, within PNCDI III and by University of Medicine and Pharmacy "Carol Davila", Contract no. 23PFE/17.10.2018 funded by the Ministry of Research and Innovation within PNCDI III, Program 1 - Development of the National RD system, Subprogram 1.2 - Institutional Performance - RDI excellence funding projects.

\section{References}

1. KASSEBAUM N.J., BERNABE E., DAHIYA M., BHANDARI B., MURRAY C.J. \& MARCENES W. Global burden of untreated caries: a systematic review and metaregression. J Dent Res, 94, 650-8 ( 2015).

2. MOREIRA R. Epidemiology of Dental Caries in the World (2012).

3. FRENCKEN J.E., SHARMA P., STENHOUSE L., GREEN D., LAVERTY D. \& DIETRICH T. Global epidemiology of dental caries and severe periodontitis - a comprehensive review. J Clin Periodontol, 44 Suppl 18, S94-S105 (2017).

4. BOYCE W.T., DEN BESTEN P.K., STAMPERDAHL J., ZHAN L., JIANG Y., ADLER N.E. \& FEATHERSTONE J.D. Social inequalities in childhood dental caries: the convergent roles of stress, bacteria and disadvantage. Soc Sci Med, 71, 1644-52 (2010).

5. ONG D.C. \& BLEAKLEY J.E. Compromised first permanent molars: an orthodontic perspective. Aust Dent J, 55, 2-14; quiz 105 (2010).

6. BHAYAT A., AHMAD M.S., HIFNAWY T., MAHROUS M.S., AL-SHORMAN H., ABUNABA'A L. \& BAKEER H. Correlating dental caries with oral bacteria and the buffering capacity of saliva in children in Madinah, Saudi Arabia. J Int Soc Prev Community Dent, 3, 38-43 (2013).

7. CARLOS J.P. \& GITTELSOHN A.M. Longitudinal studies of the natural history of caries. II. A life-table study of caries incidence in the permanent teeth. Arch Oral Biol, 10, 739-51 (1965).

8. LEKSELL E., RIDELL K., CVEK M. \& MEJARE I. Pulp exposure after stepwise versus direct complete excavation of deep carious lesions in young posterior permanent teeth. Endod Dent Traumatol, 12, 192-6 (1996).

9. BJORNDAL L., LARSEN T. \& THYLSTRUP A. A clinical and microbiological study of deep carious lesions during stepwise excavation using long treatment intervals. Caries Res, 31, 411-7 (1997).
10. KIDD E.A., JOYSTON-BECHAL S. \& BEIGHTON D. Microbiological validation of assessments of caries activity during cavity preparation. Caries Res, 27, 402-8 (1993).

11. PETROU M.A., ALHAMOUI F.A., WELK A., ALTARABULSI M.B., ALKILZY M. \& C.H.S. A randomized clinical trial on the use of medical Portland cement, MTA and calcium hydroxide in indirect pulp treatment. Clin Oral Investig, 18, 1383-9 (2014).

12. PUTNAM S., LOPATA C., FOX J., THOMEER M., RODGERS J., VOLKER M., LEE G., NEILANS E. \& WERTH J. Comparison of Saliva Collection Methods in Children with High-Functioning Autism Spectrum Disorders: Acceptability and Recovery of Cortisol. Child psychiatry and human development, 43, 560-73 (2012).

13. BJØRNDAL L. \& THYLSTRUP A. A practice-based study on stepwise excavation of deep carious lesions in permanent teeth: a 1-year follow-up study. Community Dentistry and Oral Epidemiology, 26, 122-128 (1998).

14. LEONE C.W. \& OPPENHEIM F.G. Physical and chemical aspects of saliva as indicators of risk for dental caries in humans. J Dent Educ, 65, 1054-62 (2001).

15. MEJARE I.A., AXELSSON S., DAVIDSON T., FRISK F., HAKEBERG M., KVIST T., NORLUND A., PETERSSON A., PORTENIER I., SANDBERG H., TRANAEUS S. \& BERGENHOLTZ G. Diagnosis of the condition of the dental pulp: a systematic review. Int Endod J, 45, 597-613 (2012).

16. DUMMER P.M., HICKS R. \& HUWS D. Clinical signs and symptoms in pulp disease. Int Endod J, 13, 27-35 (1980).

17. GARFUNKEL A., SELA J. \& ULMANSKY M. Dental pulp pathosis: Clinicopathologic correlations based on 109 cases. Oral Surgery, Oral Medicine, Oral Pathology, 35, 110-117 (1973).

18. RICUCCI D., LOGHIN S. \& SIQUEIRA J.F. JR. Correlation between clinical and histologic pulp diagnoses. J Endod, 40, 1932-9 (2014).

19. MALTZ M., DE OLIVEIRA E.F., FONTANELLA V. \& BIANCHI R. A clinical, microbiologic, and radiographic study of deep caries lesions after incomplete caries removal. Quintessence Int, 33, 151-9 (2002).

20. RICKETTS D.N., KIDD E.A., INNES N. \& CLARKSON J. Complete or ultraconservative removal of decayed tissue in unfilled teeth. Cochrane Database Syst Rev, CD003808 (2006).

21. SCHWENDICKE F., FRENCKEN J.E., BJORNDAL L., MALTZ M., MANTON D.J., RICKETTS D., VAN LANDUYT K., BANERJEE A., CAMPUS G., DOMEJEAN S., FONTANA M., LEAL S., LO,E., MACHIULSKIENE V., SCHULTE A., SPLIETH C., ZANDONA A. F. \& INNES N.P. Managing Carious 
Lesions: Consensus Recommendations on Carious Tissue Removal. Adv Dent Res, 28, 58-67 (2016).

22. SABER, A.M., ALTOUKHI, D.H., HORAIB, M.F., EL-HOUSSEINY A.A., ALAMOUDI, N.M. \& SABBAGH H.J. Consequences of early extraction of compromised first permanent molar: a systematic review. BMC Oral Health, 18, 59 (2018).

23. SCHWENDICKE F. \& INNES N. Removal Strategies for Carious Tissues in Deep Lesions (2018).

24. SCHWENDICKE F., PARIS S. \& TU Y.K. Effects of using different criteria for caries removal: a systematic review and network meta-analysis. J Dent, 43, 1-15 (2015).

25. RICKETTS D., LAMONT T., INNES N.P., KIDD E. \& CLARKSON J.E. Operative caries management in adults and children. Cochrane Database Syst Rev, CD003808 (2013).

26. HON L., MOHAMED A. \& LYNCH E. Reliability of colour and hardness clinical examinations in detecting dentine caries severity: a systematic review and meta-analysis. Scientific Reports, 9, 6533 (2019).

27. ORHAN A.I., OZ F.T., OZCELIK B. \& ORHAN K. A clinical and microbiological comparative study of deep carious lesion treatment in deciduous and young permanent molars. Clin Oral Investig, 12, 36978 (2008).

28. ZANATA R.L., NAVARRO M.F., BARBOSA S.H., LAURIS J.R. \& FRANCO E.B. Clinical evaluation of three restorative materials applied in a minimal intervention caries treatment approach. J Public Health Dent, 63, 221-6 (2003).
29. HAHN C.L., FALKLER W.A. JR. \& MINAH G.E. Microbiological studies of carious dentine from human teeth with irreversible pulpitis. Arch Oral Biol, 36, 147-53 (1991).

30. LOVE R.M. \& JENKINSON H.F. Invasion of dentinal tubules by oral bacteria. Crit Rev Oral Biol Med, 13, 171-83 (2002).

31. AYNA B., CELENK S., ATAKUL F., SEZGIN B. \& OZEKINCI T. Evaluation of clinical and microbiological features of deep carious lesions in primary molars. J Dent Child (Chic), 70, 15-8 ( 2003).

32. TORNHAGE C.J. Reference values for morning salivary cortisol concentrations in healthy schoolaged children. J Pediatr Endocrinol Metab, 15, 197204 (2002).

33. TIKHONOVA S., BOOIJ L., D'SOUZA V., CROSARA K.T.B., SIQUEIRA W.L. \& EMAMI E. Investigating the association between stress, saliva and dental caries: a scoping review. BMC oral health, 18, 41-41 (2018).

34. PANI S.C., ABUTHURAYA D., ALSHAMMERY H.M., ALSHAMMERY D. \& ALSHEHRI H. Salivary cortisol as a biomarker to explore the role of maternal stress in early childhood caries. Int $J$ Dent, 2013, 565102 (2013).

35. BARBOSA T., CASTELO P., LEME M. \& GAVIÃO M. Associations between oral health-related quality of life and emotional statuses in children and preadolescents. Oral diseases, 18, 639-47 (2012).

36. RAI K., HEGDE A.M., SHETTY S. \& SHETTY S. Estimation of salivary cortisol in children with rampant caries. J Clin Pediatr Dent, 34, 249-52 (2010). 